\title{
Multiplexed Assessment of the Southwest Oncology Group-Directed Intergroup Breast Cancer Trial S9313 by AQUA Shows that Both High and Low Levels of HER2 Are Associated with Poor Outcome
}

\author{
Malini Harigopal, ${ }^{*}$ William E. Barlow, ${ }^{\dagger}$ \\ Greg Tedeschi, ${ }^{\neq}$Peggy L. Porter, ${ }^{\S}$ I-Tien Yeh, ${ }^{\text {" }}$

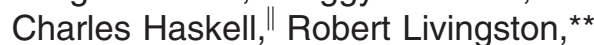 \\ Gabriel N. Hortobagyi, ${ }^{\dagger \dagger}$ George Sledge, ${ }^{\ddagger \neq}$ \\ Charles Shapiro, ${ }^{\S \S}$ James N. Ingle, ${ }^{\text {,ाTा }}$ David L. Rimm, ** \\ and Daniel F. Hayes ${ }^{|l|}$

\begin{abstract}
From the Department of Pathology,* Yale University School of Statistical Center, ${ }^{\dagger}$ Seattle, Washington; HistoRx Inc., ${ }^{\ddagger}$ New Haven, Connecticut; the Fred Hutchinson Cancer Research Center, ${ }^{\S}$ Seattle, Washington; University of Texas Health Science Center at San Antonio," San Antonio, Texas; the UCLA Medical Center," Santa The University of Texas M.D. Anderson Cancer Center, ${ }^{\text {th }}$ Houston, Texas; the Cancer Pavilion, Indiana University Medical Center, Indianapolis, Indiana, the Arthur James Cancer Center Hospital, ${ }^{\$ 5}$ Obio State University, Columbus, Ohio; the Cancer and Leukemia Group B Medical Oncology, "बा Mayo Clinic, Rochester, Minnesota; and the University of Michigan Comprehensive Cancer Center, ${ }^{|l|}$ Ann Arbor, Michigan
\end{abstract} \\ Medicine, New Haven, Connecticut; the Southwest Oncology Group \\ Monica, California; the Arizona Cancer Center,** Tucson, Arizona;
}

Assessment of key breast cancer tissue biomarkers is often done using nonquantitative methods. We hypothesized that use of continuous analysis of expression with the AQUA method of automated quantitative analysis will provide prognostic information beyond that attainable with conventional methods. A tissue microarray was made from 2123 of 3122 patients accrued to SWOG 9313, in which sequential doxorubicin (A) and cyclophosphamide (C) was compared with combination AC and in which all patients except premenopausal estrogen receptor (ER)-negative patients received tamoxifen. Multiplexed assays of 1) HER2 and estrogen receptor and 2) progesterone receptor (PgR) and $\mathbf{p 5 3}$ were performed on the two slides using the immunofluorescence-based AQUA method of automated quantitative analysis. Both ER and PgR showed unimodal distributions and significantly predicted disease-free survival when tested as continuous variables and adjusted for node status, tumor size, treatment, and menopausal status $(P=0.005$ and $P<$
0.001 , respectively). HER2, measured as a continuous variable, showed a biphasic effect on disease-free survival. Both high and low expressers of HER2 have worse outcomes (when low levels are equivalent to that seen in normal breast ducts). In patients who were uniformly treated with AC chemotherapy and tamoxifen (when indicated), both ER and PgR, assessed as continuous variables, were highly prognostic, whereas p53 expression was not. This assay method may provide a new companion diagnostic approach for targeted therapies. (Am J Pathol 2010, 176:1639-1647; DOI: 10.2353/ajpath.2010.090711)

Accurate assessment of tissue biomarkers is now a cornerstone of management in breast cancer. Estrogen receptor (ER) and progesterone receptor (PgR) are two key

Supported by National Institutes of Health (grant R33-CA106709 to D.L.R.) and by a grant from the Breast Cancer Research Foundation (to P.P.) and in part by the following US Public Health Service Cooperative Agreement grants awarded by the National Cancer Institute, Department of Health and Human Services: CA32102, CA38926, CA49883, CA21155, CA77658, CA25224, CA31946, CA32291, CA37891, CA35431, CA45377, CA58416, CA22433, CA58686, CA46113, CA04919, CA46441, CA58861, CA46282, CA35261, CA27057, CA76132, CA35192, CA76447, CA76462, CA45450, CA76429, CA63845, CA12644, CA20319, CA63844, CA45560, CA58415, CA14028, CA58658, CA42777, CA35119, CA35090, CA35117, CA13612, CA16385, CA67575, CA68183, CA46368, CA04920, CA74647, and CA52654 (Southwest Oncology Group); CA21115 and CA49883 (Eastern Cooperative Oncology Group); CA31946, CA33601, and CA77658 (Cancer and Leukemia Group B); and CA25224 (North Central Cancer Treatment Group).

Accepted for publication December 16, 2009.

Supplemental material for this article can be found on http://ajp. amjpathol.org.

D.L.R. declares a duality of interest as a founder, consultant, and stockholder of a biotech company called HistoRx. This company was founded by Yale University and is the exclusive Yale licensee of the AQUA technology developed in Dr. Rimm's laboratory.

Address reprint requests to David L. Rimm, M.D., Ph.D., Department of Pathology, Yale University School of Medicine, 310 Cedar St., P.O. Box 208023, New Haven, CT 06520-8023. E-mail: david.rimm@yale.edu. 
prognostic and predictive tissue biomarkers that have been used for more than three decades. ER status, first measured by ligand-binding assay and then by immunohistochemistry, is the most important variable in predicting response to endocrine therapy and is recommended for routine evaluation of all breast cancer biopsy specimens. ${ }^{1-7} \mathrm{PgR}$, an ER-regulated protein, has been shown by several studies to be associated with response to endocrine therapy. ${ }^{3,8-10}$ Previous studies have shown that $\mathrm{ER}$ and $\mathrm{PgR}$ have similar prognostic and predictive value and that there is a strong correlation between ER and $\mathrm{PgR}$ measured by immunohistochemistry $(\mathrm{IHC})$ and by ligand-binding assays. ${ }^{8,9,11,12}$ However, recently it has been noted that the mechanism of measurement affects the distribution of the expression level results in any given population. ${ }^{13,14}$

HER2 is the product of the c-erbB-2 (HER2/neu) gene that is a member of the class of oncogenes associated with receptor tyrosine kinases. Similarly to that for ER and $\mathrm{PgR}$, determination of HER2 expression is also recommended for all breast cancer biopsy specimens ${ }^{15}$ to determine the use of anti-Her2 therapies such as trastuzumab and lapatinib. HER2, as measured by $\mathrm{IHC}$ or fluorescent in situ hybridization, has shown a unimodal relationship with outcome in which high-level expression was associated with worse outcome in patients treated before the era of trastuzumab therapy. However, in a few small studies, when quantitative methods of protein expression were used (either enzyme-linked immunosorbent assay or AQUA), both high and low levels of expression of HER2 showed an impact on patient prognosis. ${ }^{16,17}$

The tumor suppressor protein p53 has been a controversial marker in breast cancer. A meta-analysis performed 10 years ago showed that mutations indicated an independent relative risk. ${ }^{18}$ However, an update on tumor marker recommendations in 2007 did not include p53 in the list of markers recommended for routine clinical practice. ${ }^{7}$ This omission could be due to the subjective nature of $\mathrm{IHC}$ or the inherent variability of protein expression as a function of the location of the p53 mutation. For example, missense mutations in exons 5 to 8 frequently lead to overexpression of nonfunctional p53, whereas other mutations can lead to loss of expression. ${ }^{19}$ Furthermore, when assessed quantitatively using AQUA, a continuous analysis shows a U-shaped relationship with outcome. ${ }^{16}$ Thus, the value of p53 protein expression levels is still unclear.

Although a number of methods have been used, the current standard approach to evaluate most of these markers is the use of chromogenic $\mathrm{IHC}$ followed by subjective assessment by a pathologist. In the case of HER2, fluorescent in situ hybridization is also widely used. The subjective and nonquantitative nature of this standard has led to numerous problems ${ }^{20}$ and nationwide efforts toward standardization. ${ }^{21}$ Moreover, the standard methods have obscured statistical characteristics of patient populations and possibly decreased the prognostic value of these tests. Automated quantitative analysis, based on an immunofluorescent platform, has been developed to obtain standardized, objective, and reproducible measurements of tissue biomarkers. ${ }^{22,23}$ In this study, we have used this platform (now called AQUA) to assess ER, PgR, HER2, and p53 protein expression on a large set of tissues collected from patients with modest risk and stage I and II breast cancer who were treated with doxorubicin (A) and cyclophosphamide (C) (AC) chemotherapy in a prospective, randomized clinical trial (Southwest Oncology Group [SWOG] S9313/Intergroup [Eastern Cooperative Group, North Central Cancer Treatment Group, and Cancer and Leukemia Group B] 0137 Protocol).

\section{Materials and Methods}

Patient selection, assay performance, and data analysis are reported according to the REMARK criterion. ${ }^{24}$ Tissue microarrays (TMAs) used for this study were previously constructed in Seattle using paraffin blocks collected prospectively from patients who participated in SWOG S9313/Intergroup 0137. SWOG S9313 was an adjuvant chemotherapy trial that accrued 3125 eligible women with early-stage breast cancer between April 1994 and May 1997. ${ }^{25}$ Participants were required to have metastatic involvement of one to three axillary lymph nodes or to have high-risk node-negative breast cancer, defined as primary tumors $>2 \mathrm{~cm}$ in size or $>1 \mathrm{~cm}$ for tumors that were both estrogen receptor- and progesterone receptor-negative. Patients were randomly assigned to treatment with one of two alternative dose schedules of doxorubicin and cyclophosphamide. Radiation therapy was recommended for all women who had breast preservation and for women with mastectomy at the treating physician's discretion. Adjuvant tamoxifen for 5 years was recommended for all women with ER-positive breast cancer or for those who were postmenopausal after the conclusion of adjuvant chemotherapy and radiation. As reported previously, there was no difference in diseasefree or overall survival for patients treated on the two randomly assigned chemotherapy arms in \$9313. ${ }^{25}$ Therefore, this patient population represents a homogeneously treated and prospectively followed group of patients treated with AC chemotherapy.

\section{Construction of Tissue Microarrays}

TMAs were constructed from formalin-fixed, paraffin-embedded primary tumor tissue blocks from 2123 of the $3125(67 \%)$ patients who participated in S9313. Tissue collection was voluntary and required a separate consent. All patients provided written informed consent to participate in S9313 as well. For control and standardization purposes, a cohort of selected breast cancer cases were arrayed from tissue in the Yale Pathology archives. ${ }^{16,22}$ TMAs for 9313 tissues were prepared as a set of duplicate master blocks, each containing 480 cores, for a total of 28 masterblocks. Three tumor cores and three cores of normal breast epithelium were included for each patient whenever possible. The S9313 TMAs have been used for previous studies of cyclin $\mathrm{E}$ and $\mathrm{p} 27^{26}$ as well as Her2 and topoisomerase $11 .{ }^{27}$ A consort diagram of the cohort and cases assayed in the 
TMAs is shown in supplemental Figure 1 (see http://ajp. amjpathol.org).

\section{Fluorescence-Based Immunohistochemistry and Automated Quantitative Analysis}

Tissue sections were deparaffinized and rehydrated before heat induced-antigen retrieval by pressure cooking in citrate buffer $(\mathrm{pH} \mathrm{6.0)}$ for approximately 15 minutes. Endogenous peroxidase activity was quenched in a mixture of methanol and 3\% hydrogen peroxide for 30 minutes. Before placement of the primary antibody, nonspecific antibody binding was blocked with $10 \%$ BlockHen (Aves Labs Inc., Tigard, OR). After washes in $1 \times$ Trisbuffered saline (TBS) with $0.5 \%$ Tween for 10 minutes and once in $1 \times$ TBS for 5 minutes, the slides were preincubated for 1 hour at room temperature with chicken anti-human cytokeratin antibody (1:500) produced by the Rimm Laboratory. The slides were then incubated with the first primary antibody, either anti-HER2 (rabbit polyclonal diluted at 1:2000, Dako, Carpinteria, CA) or antiPgR (rabbit monoclonal, clone pS190, Epitomics, Burlingame, CA) diluted 1:100 and then incubated overnight at $4^{\circ} \mathrm{C}$ in a humidity chamber. After incubations, all slides were washed in TBS-Tween and TBS and then with corresponding secondary antibody, Сy3 conjugated donkey anti-chicken (Jackson ImmunoResearch Laboratories, Inc., West Grove, PA) diluted 1:250 in horseradish peroxidase-conjugated Envision anti-rabbit (to detect HER2 or $\mathrm{PgR}$ ) added for 1 hour at room temperature in a humidified chamber in the dark. After washes in $1 \times$ TBS with $0.5 \%$ Tween for 10 minutes and once in $1 \times$ TBS for 5 minutes, fluorescent Cy5-tyramide (PerkinEImer Life and Analytical Sciences, Boston, MA) was diluted 1:50 in amplification diluent (PerkinEImer Life and Analytical Sciences) and used for primary target identification (HER2 or PgR). To multiplex, slides were then incubated with a second target anti-ER $\alpha$ primary antibody (mouse monoclonal antibody clone 1D5 at 1:50, Dako) or anti-p53 primary antibody (mouse monoclonal clone D0-7 at 1:100, Dako) followed by washes. Before addition of a second set of horseradish peroxidase detection reagents, the primary set was quenched irreversibly with a mixture of benzoic hydrazide (100 mmol/L) and 50 $\mathrm{mmol} / \mathrm{L}$ hydrogen peroxide (freshly made). Then horseradish peroxidase-conjugated Envision anti-mouse antibodies were applied for 1 hour at room temperature in bovine serum albumin-TBS. Visualization was achieved by incubation with biotinylated tyramide for 15 minutes. Alexa 750 (Cy7) goat anti-mouse conjugated to streptavidin was used to detect the second target (ER or p53). Nuclei were visualized with 4,6-diamidino-2-phenylindole included in the secondary antibodies.

\section{Image Acquisition}

Automated image capture was performed with the HistoRx PM-2000 tissue analyzer (HistoRx, Inc., New Haven, CT). High-resolution, 8-bit (resulting in 256 discrete intensity values per pixel of an acquired image) digital images of the cytokeratin staining visualized with Cy3 and 4,6-diamidino-2-phenylindole and target staining with Cy5 were captured and saved for every histospot on the array. Pixels were written to image files as a function of power (power $[p]=$ pixel intensity/256/exposure time) to help compensate for experimental variations in staining intensity. In- and out-of-focus images were taken for each channel for future use with the AQUA script and validation program. After image acquisition, automated validating software was run on each tissue spot, eliminating spots with insufficient epithelial tissue as defined by keratin staining or eliminating spots based on a series of other variables associated with artifacts. However, AQUA was run on both validated and nonvalidated spots to determine whether the validation introduced bias into the analysis. The study reported here uses only the validated results. In each case, there were a maximum of three spots for each patient. If three or two spots were present, the result was averaged; if only one spot was available, it was accepted as the score for the case.

\section{AQUA Analysis of the Images}

Image analysis was performed using the AQUA software as described previously. ${ }^{16,22}$ For these studies, HistoRx version 1.5 of the AQUA software was used. In brief, AQUA analysis is done using a tumor-specific mask generated by manually thresholding the image of cytokeratin that distinguishes tumor from surrounding stroma and/or leukocytes. This creates a binary mask; each pixel is either "on" or "off." Thresholding levels were verified and adjusted whenever required by spot-checking a small sample of images, and the remaining images were automatically masked using the single determined threshold value. All subsequent image manipulations involve only image information from the masked area. Two images (one in-focus, one out-of-focus, $8 \mu \mathrm{m}$ deeper into the sample) were taken of the compartment-specific tags and the target marker. A percentage of the out-of-focus images was subtracted from the in-focus image, based on a pixel by pixel analysis of the two images using an algorithm called RESA (rapid exponential subtraction algorithm). This algorithm enhances the interface between areas of higher intensity staining and adjacent areas of lower intensity staining, allowing more accurate assignment of pixels to specific compartments. The PLACE (pixel locale assignment for compartmentalization of expression) algorithm assigns each pixel in the image to a specific subcellular compartment. Unlike in previous efforts, in which AQUA scores were standardized to absolute amounts of protein, ${ }^{28,29}$ in this study, only relative comparisons between AQUA scores were used.

\section{Validation of Multiplexed Assessment of Protein Expression}

Multiplexing using conventional biomarkers was performed by pairing HER2 (membrane marker) with ER (nuclear marker) on one slide and p53 (nuclear marker) with PgR (nuclear marker) on another slide. The distribu- 

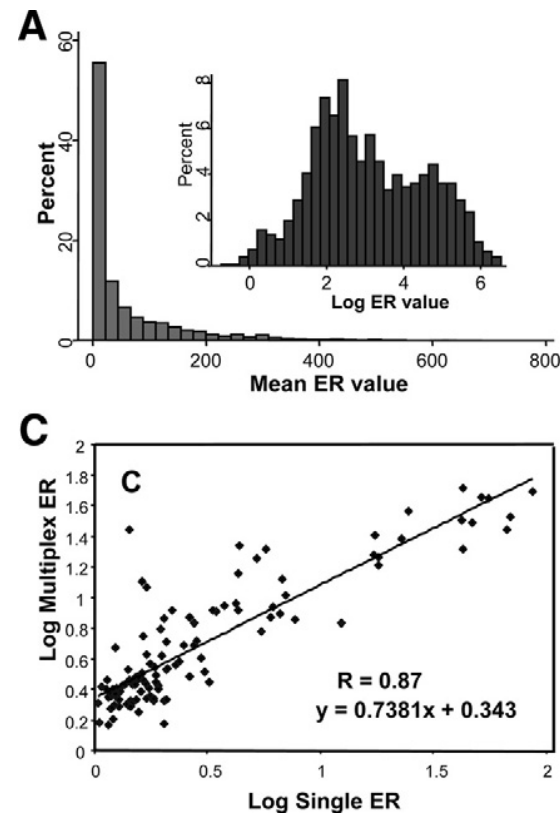

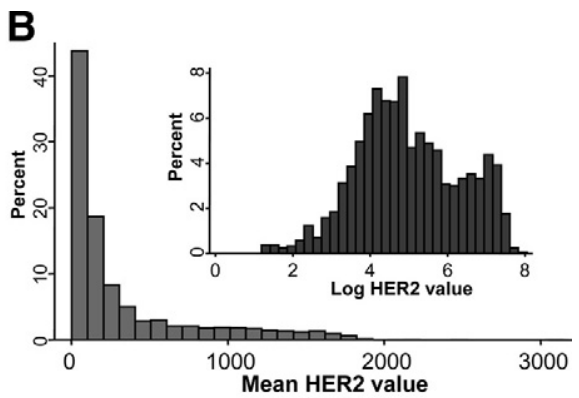

D

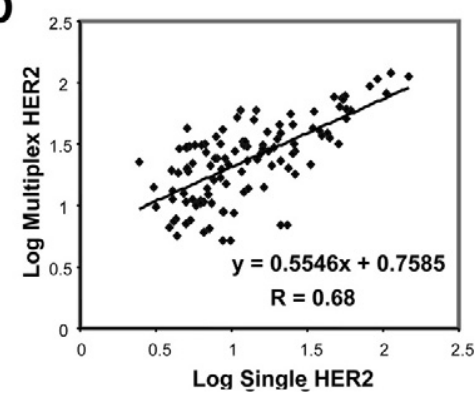

Figure 1. Distribution of expression of ER (A) and HER2 (B) in the study population is shown with log transformation of the data in the insets. C: Validation of multiplexing data is shown by comparison of single ER versus multiplexed (double) HER2 with ER on a control TMA using tissues from the Yale Pathology Archives. D: Single HER2 versus multiplexed (double) HER2 with ER. Similar results were seen for PgR and p53 (not shown). AQUA levels for each protein are presented on the $y$ axis as arbitrary units. tions of expression of both ER and HER2 are typical of those seen in previous studies in which there was quantitative assessment of expression of these biomarkers $^{22,28}$ (Figure 1, A and B). To exclude interference or overflow from one marker to the second, parallel staining was performed on selected sets of Yale tissue samples (YTMA-94) as controls for each staining run. Preliminary results from our laboratory using a multiplexing technique on test arrays have shown that multiplexing two primary antibodies gives results that are reproducible and indistinguishable from analysis of each marker individually. Linear regressions were performed to compare ER by itself on serial sections from a control array to ER performed in a multiplexed fashion with HER2. The correlations between ER (single) compared with ER (multiplexed with HER2) and HER2 (single) compared with HER2 (multiplexed with ER) were excellent $(r=0.87$ and $r=0.68$, respectively) (Figure 1, C and D), and similar correlations were seen for PgR and p53 (not shown). In contrast, the correlations between single ER and HER2 and between single PgR and p53 were poor $(r=0.06$ and $r=0.15$, respectively), ruling out any artifactual relationships among the multiplexed markers.

\section{Statistical Analysis}

The primary trial end point was disease-free survival (DFS) defined as the time to first recurrence (local, regional, or distant), new primary cancer in the contralateral breast, or death of any cause, as per the clinical protocol. ${ }^{25}$ Overall survival was defined as the time to death of any cause. Patients were censored on the date of last contact if a treatment failure event had not been observed. The distribution of DFS was estimated using the Kaplan-Meier method. Cox proportional hazards regression analysis was used to estimate hazard ratios (HRs) and $95 \%$ confidence intervals (Cls) and included possible adjustment for treatment assignment, tumor size $(<2$,
2 to 5 , or $>5 \mathrm{~cm})$, number of positive lymph nodes $(0,1$, 2 , or 3), and menopausal status. We did not adjust for hormone receptor status (both ER and PgR negative versus either positive by local institutional standards) because these variables were being directly investigated. All reported $P$ values and confidence intervals are from two-sided tests. Spearman rank correlation was used to assess the association between biomarkers. Statistical analyses were performed by StatView software programs (SAS Institute Inc., Cary, NC), SPSS, and STATA programs. Continuous ER, PgR, HER2, and p53 were logged because they were extremely positively skewed. Statistical testing was done with different cutoffs as described below to determine the sensitivity of the results to the choice of cut point.

\section{Results}

\section{Patient and Tumor Characteristics}

Of the 3114 eligible patients in the trial, 1715 cases were used in the analysis because of incomplete tissue collection for the TMAs and tissue loss in processing. Cases were used if they had at least one validated marker with a quantitative (AQUA) score $(55.1 \%$ of total, but $81 \%$ of cases with tissue available). Absence of cores in the TMA blocks, core loss (less than 10\% tumor), and absence of invasive carcinoma resulted in the exclusion of many cores from analysis (a summary of cases included in each step of the process is shown in supplemental Figure 1, see $h$ ttp://ajp.amjpathol.org). Disease-free survival did not differ between those with validated markers and those without $(P=0.42)$ by Kaplan-Meier analysis. Patients with TMA cores included in this study did not differ significantly from those without tissue samples on age, menopausal status, or receptor status. Included patients had slightly larger tumors $(P=0.049)$ and slightly more 
Table 1. Cox Univariate and Multivariate Analysis for DFS

\begin{tabular}{|c|c|c|c|c|}
\hline \multirow[b]{2}{*}{ Marker } & \multicolumn{2}{|c|}{ Unadjusted } & \multicolumn{2}{|c|}{ Adjusted* } \\
\hline & $\mathrm{HR}(95 \% \mathrm{Cl})$ & $P$ & $\mathrm{HR}(95 \% \mathrm{Cl})$ & $P$ \\
\hline ER (In) & $0.92(0.86-0.98)$ & 0.016 & $0.90(0.84-0.97)$ & 0.005 \\
\hline $\operatorname{PgR}(\ln )$ & $0.89(0.84-0.95)$ & 0.001 & $0.88(0.83-0.94)$ & $<0.001$ \\
\hline HER2 (In) & $1.01(0.93-1.09)$ & 0.82 & $1.01(0.93-1.09)$ & 0.85 \\
\hline P53 (In) & $0.94(0.87-1.02)$ & 0.12 & $0.94(0.87-1.02)$ & 0.16 \\
\hline
\end{tabular}

*Adjusted for randomized treatment, menopausal status, tumor size, and number of positive nodes.

positive nodes $(P=0.033)$ than patients without tissue samples. For those with markers for which AQUA was successfully performed, $45 \%$ were hormone receptornegative, as determined at the primary institution, and $53 \%$ had one or more positive nodes. Disease-free survival and overall survival did not differ between those with markers and those without after adjustment for prognostic factors so the sample is representative of the entire trial population as described. ${ }^{25}$

\section{Correlation between AQUA Analysis and Disease Outcomes}

AQUA scores for all four markers (ER, PgR, p53, and HER2) were assessed for prognostic value with respect to DFS using continuous univariate analysis and also by distribution into quartiles. Log AQUA ER was statistically significantly associated with DFS when assessed as a continuous variable using Cox proportional hazards $(P=$ 0.016) (Table 1) but was not significant when categorized into quartiles $(P=0.10)$ (Figure $2 A)$. If the adjusted analysis of $\log$ AQUA ER is restricted to those originally called ER-positive by local institutional standards, then log AQUA ER becomes nonsignificant although the hazard ratio still indicates some remaining prognostic effect $(\mathrm{HR}=0.93$; 95\% Cl 0.83-1.04; $P=0.19)$. Log AQUA PgR was highly significant when assessed as a continuous variable $(P=0.001)$ (Table 1$)$ and when categorized into quartiles $(P=0.006)$ (Figure $2 \mathrm{~B})$. If the adjusted analysis of $\log$ AQUA PgR is restricted to those originally called PgR-positive by local institutional standards, then log AQUA PgR becomes nonsignificant but with a strong trend $(\mathrm{HR}=0.91 ; 95 \% \mathrm{Cl} 0.83-1.01 ; P=0.07)$. Continuous log AQUA HER2 was not significant when unadjusted or adjusted for number of positive nodes, tumor size, treatment, and menopausal status $(P=0.82$ and 0.85 , respectively) and barely significant when catego- rized into quartiles $(P=0.048$ ) (Figure $2 C$ ). Expression of AQUA p53 was not significantly associated with DFS by any method of analysis, adjusted or unadjusted (data not shown).

Regression analysis showed moderate correlation between AQUA ER and AQUA PgR (Pearson $r=0.43, P<$ 0.0001 ; Spearman $r=0.48$ ), but there were clearly cases that were high for one protein and low for the other (Figure 3A). Surprisingly, AQUA ER and HER2 were weakly positively correlated overall (Pearson $r=0.17$, $P<0.0001$; Spearman $r=0.47$ ) This finding was enigmatic, because ER and HER2 are usually negatively correlated. ${ }^{30}$ Therefore, we analyzed the relationship between AQUA ER and HER2 expression more carefully and found that this curious observation was related to the ability to quantitatively evaluate expression of HER2 at very low levels (in the range of normal breast epithelial cell expression). At these levels, ER was strongly correlated (Pearson $r=0.46, P<0.0001$; Spearman $r=0.46$ ) for those in the lowest quartiles of AQUA ER and HER2 (Figure 3B). No association was seen between AQUA HER2 and AQUA PgR (Figure 3C) (Pearson $r=-0.02$, $P=0.57$; Spearman $r=0.14$ ) or AQUA HER2 and AQUA p53 (not shown).

Previous studies by a number of groups have suggested that overexpression and/or amplification of HER2 is associated with worse prognosis. ${ }^{31}$ However, a few studies have suggested that very low levels of HER2, roughly equivalent to that seen in normal breast epithelial cells, are paradoxically associated with poor prognosis. $^{32,33}$ Likewise, in the $\$ 9313$ cohort both the top and bottom deciles had worse DFS than the middle $80 \%$ (log rank $P=0.012$ ) (Figure 4A). When analyzed as a continuous variable, plotting hazard ratio for recurrence against log HER2 expression level, we observed a U-shaped relationship with both high and low HER2 expression associated with poor outcome (Figure 4B).
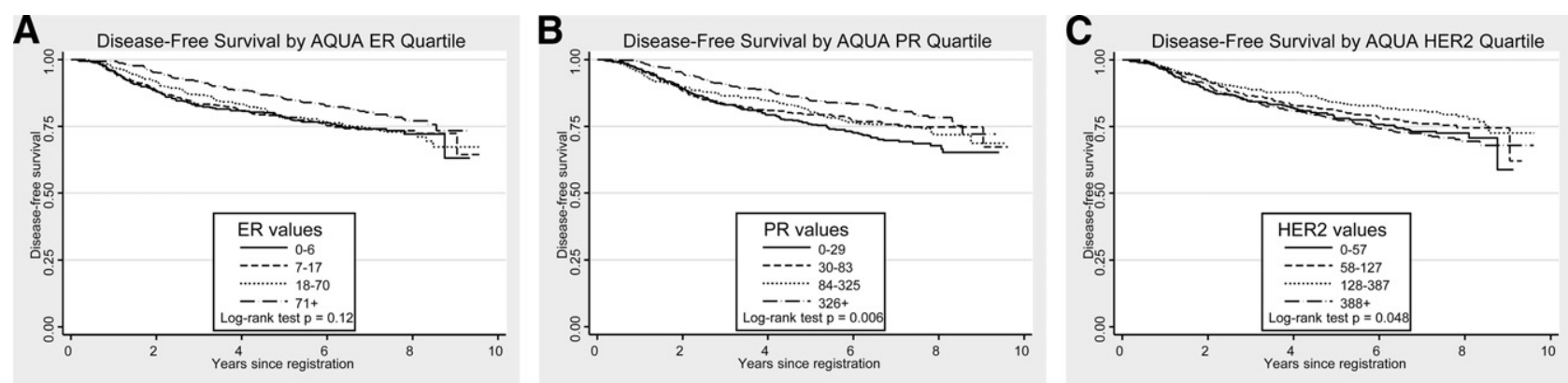

Figure 2. Kaplan-Meier survival plot for DFS by AQUA ER (A), PR (B), and HER2 (C), all split into quartiles. 
A

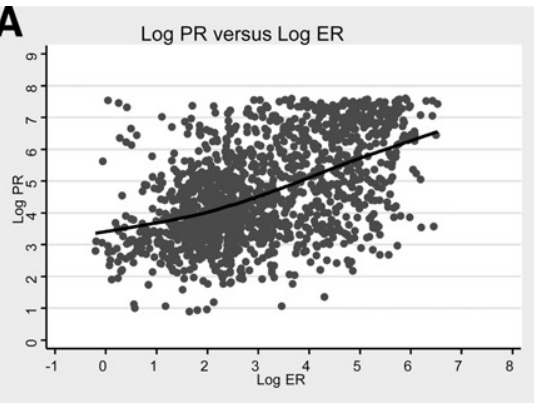

B

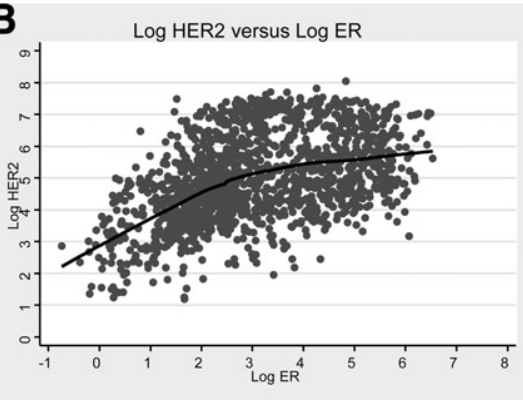

C

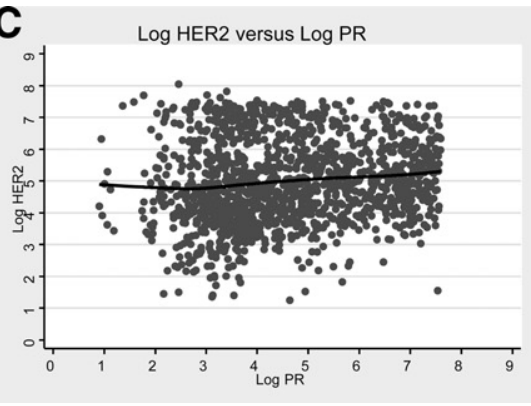

Figure 3. A: Relationships between the log AQUA scores of ER, PR, and HER 2 show that ER and PR are moderately highly correlated (Pearson $r=0.43$, $P<0.0001$; Spearman $r=0.48$ ). B: The relationship between HER2 and ER is more complete, showing a correlation for low ER and HER2 that is lost at higher levels. The dotted line shows the lowest decile of HER2 AQUA scores. C: No relationship is seen between PgR and HER2.

\section{Discussion}

Using the immunofluorescence-based AQUA method of automated quantitative analysis with multiplexing technology, we assessed two pairs of biomarkers on each specimen from SWOG 9313 using either ER and HER2 or $\mathrm{PgR}$ and p53 pairs. Validation of multiplexing technology was proven by showing that the single marker expression was highly correlated to expression as part of a multiplexed pair, but completely unrelated to its partner in the multiplexed pair. Recently, a number of groups have begun multiplexing $\mathrm{IHC}$ to assess multiple markers on the same slide ${ }^{34-38}$ to maximize use of scarce tissue resources and/or optimally assess the colocalization of multiple protein targets. However, multiplexing has been rarely validated using the method we have shown above, comparing single to multiplexed staining. The potential benefits of multiplexing are visualization of two or more markers simultaneously and optimization of scarce tissue resources. In addition, confounding variables such as tumor heterogeneity can be minimized because multiple markers are assessed in the same section of the tumor in the same cells. This strength may be exploited more in future studies in which we will determine whether pairs of markers (such as ER and Ki-67) will allow conclusions not obtainable by single assessment of each.

Our results confirm the importance of both ER and PgR as significant predictors of DFS in patients with earlystage breast cancer treated with AC chemotherapy and, when appropriate, tamoxifen. This observation was made when both were tested as continuous variables, adjusted for node status, tumor size, treatment, and menopausal status. This large cohort of uniformly treated women shows a unimodal pattern of ER and PgR expression, which is similar to that in some previous large studies, but in contrast to some that show a bimodal distribution. ${ }^{39,40}$ It has been suggested that the method of measurement of expression may affect the distribution. ${ }^{13}$ However, it is possible that the bimodality of ER expression reported for some cohorts is an artifact of the scoring system. ${ }^{14}$ Specifically, when scored quantitatively, either by ligandbinding assay or similar quantitative method, the distribution is unimodal compared with pathologist-based subjective systems that often show bimodality. In this large cohort, we have confirmed the unimodal nature of the ER, assessed by a quantitative method (AQUA). The biological and medical implications of this observation in the current environment are minimal, but this could change as options for endocrine therapy increase.

Our data suggest that measures of expression currently used in the clinic are inaccurate at both the low and high ends of the scales. Indeed, several decades ago, ER was assayed using a quantitative ligand-binding assay that provided a much more dynamic range than does the semiquantitative, and much more subjective, analysis by immunohistochemistry. ${ }^{41}$ These early studies suggested that prognosis and in particular clinical benefit related to antiestrogen therapy were correlated with increasingly higher ER levels, not just positive or negative determinations. ${ }^{42}$ Quantitative analysis of ER and also of $\mathrm{PgR}$ and HER2 at very low and high levels is lost using either immunohistochemistry or, in the case of HER2, fluorescent in situ hybridization. This loss of sensitivity in the low expression range is due to the titers selected for routine clinical assays for $\mathrm{HHC}^{28}$ and the fact that amplification by fluorescent in situ hybridization is not strictly proportional to protein expression. ${ }^{43}$ As the number of
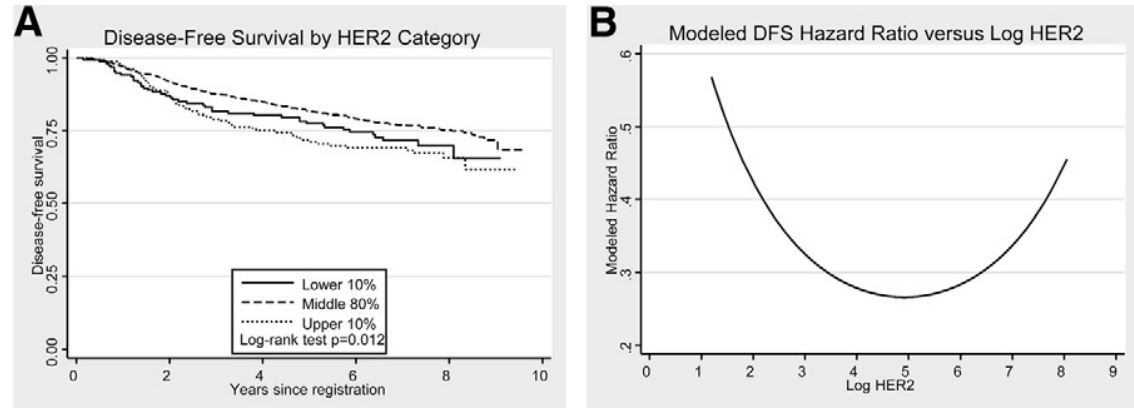

Figure 4. A: Kaplan-Meier analysis of HER2 AQUA shows that both the top and bottom deciles have worse DFS than the middle $80 \%(\log$ rank $P=0.012$ ). B: Modeling the continuous hazard ratio against the log of the HER2 AQUA score shows a U-shaped relationship. 
options for endocrine and anti-HER2 therapy increases, one can envision trials in which the level of expression helps to define which patients have the best response to alternative endocrine therapies. ${ }^{44}$

Indeed, quantitative determination of HER2 may be even more important than that for ER, because of its bimodal expression pattern. In this study, we observed that AQUA HER2 had a biphasic association with outcome, with worse prognosis for both very low and very high levels (Figure 4). This finding is not novel. More than a decade ago, Koscielny et al ${ }^{33}$ measured HER2 in frozen tissue quantitatively using an enzyme-linked immunoassay and reported that prognosis was particularly poor for patients who had either high or low levels of HER2. Subsequent studies, using either RT-PCR or AQUA, have supported this finding. 32,45 The current study, which represents the largest of its kind, especially in which patients have been uniformly treated and followed, confirms these results.

Importantly, we speculate that the association between very low HER2 and low ER and poor outcome may represent the identification of a subset of patients who have recently been designated as "triple-negative"; that is, they are negative for expression of ER, PgR, and HER2. This phenotype has been associated with the "basal-like" subtype of breast cancer when analyzed by multigene expression arrays. ${ }^{46}$ It has been reported that these triple-negative tumors confer a particularly poor outcome. However, it is clear that not all patients who have so-called triple-negative breast cancer have a particularly bad prognosis, and furthermore many of these patients will benefit substantially from adjuvant chemotherapy. ${ }^{47,48}$ These observations suggest that not all patients with negative ER, PgR, and HER2 are the same. Some authors have proposed that currently available immunohistochemical assays might distinguish this basal subgroup from others within the triple-negative category. ${ }^{49,50}$ However, IHC assays are inherently poor for quantifying protein at very low levels. Thus, IHC assays will not identify women with very low HER2 in the ER-negative, PgR-negative subgroup that may have a particularly unfavorable prognosis, even when they receive AC chemotherapy. We propose that, using the quantitative AQUA approach, such patients (ER- and PgR-negative with very low HER2) can be identified and might represent the triple-negative subgroup with a particularly poor prognosis.

In light of recent recommendations for standardization of assessment of HER2 (and soon ER) by American Society of Clinical Oncologists/College of American Pathologists panels, ${ }^{21}$ these findings highlight the importance of an accurate and standardized assessment of biomarkers to select subsets of patients for specific management. Whereas this study shows that both ER and PgR as a continuous variable are highly prognostic, it remains to be determined whether this type of specific information can help to select patients for specific endocrine therapies. The strength of this study is that it represents a large group of women who were prospectively evaluated and followed after uniform treatment. However, the design of the clinical trial and the equivalence of the two chemo- therapy arms preclude us from assessing any predictive role for AQUA ER or HER2 in regard to endocrine therapy or chemotherapy. Ongoing studies in other datasets are addressing these important issues.

In summary, AQUA staining for multiple markers, in particular ER and HER2, appears to provide a biologically interesting and perhaps potentially clinically useful quantitative analysis associated with prognostic outcomes in patients with early-stage breast cancer treated with AC chemotherapy. In particular, our observation that patients with very low levels of HER have a worse prognosis suggests that the automated AQUA semiquantitative immunofluorescent approach may provide important data not available with conventional immunohistochemical assays. Although still relatively new, the AQUA software is seeing increasing distribution (more than 20 sites) and is now available on the Aperio FL platform, suggesting broad future availability for use as described in this work.

\section{Acknowledgments}

We acknowledge Mark Gustavson and Veronique Neumeister for their assistance with AQUA.

\section{References}

1. Allred DC, Bustamante MA, Daniel CO, Gaskill HV, Cruz AB Jr: Immunocytochemical analysis of estrogen receptors in human breast carcinomas. Evaluation of 130 cases and review of the literature regarding concordance with biochemical assay and clinical relevance. Arch Surg 1990, 125:107-113

2. Allred DC, Harvey JM, Berardo M, Clark GM: Prognostic and predictive factors in breast cancer by immunohistochemical analysis. Mod Pathol 1998, 11:155-168

3. Clark GM, McGuire WL, Hubay CA, Pearson OH, Marshall JS: Progesterone receptors as a prognostic factor in stage II breast cancer. N Engl J Med 1983, 309:1343-1347

4. Goulding H, Pinder S, Cannon P, Pearson D, Nicholson R, Snead D, Bell J, Elston CW, Robertson JF, Blamey RW, Ellis IO: A new immunohistochemical antibody for the assessment of estrogen receptor status on routine formalin-fixed tissue samples. Hum Pathol 1995, 26:291-294

5. Jonat W, Maass H, Stegner HE: Immunohistochemical measurement of estrogen receptors in breast cancer tissue samples. Cancer Res 1986, 46:4296s-4298s

6. McCarty KS Jr, Miller LS, Cox EB, Konrath J, McCarty KS Sr: Estrogen receptor analyses. Correlation of biochemical and immunohistochemical methods using monoclonal antireceptor antibodies. Arch Pathol Lab Med 1985, 109:716-721

7. Harris L, Fritsche H, Mennel R, Norton L, Ravdin P, Taube S, Somerfield MR, Hayes DF, Bast RC Jr: American Society of Clinical Oncology 2007 update of recommendations for the use of tumor markers in breast cancer. J Clin Oncol 2007, 25:5287-5312

8. Elledge RM, Green S, Pugh R, Allred DC, Clark GM, Hill J, Ravdin P Martino S, Osborne CK: Estrogen receptor (ER) and progesterone receptor (PgR), by ligand-binding assay compared with ER. PgR and pS2, by immuno-histochemistry in predicting response to tamoxifen in metastatic breast cancer: a Southwest Oncology Group Study. Int J Cancer 2000, 89:111-117

9. Pertschuk LP, Feldman JG, Kim YD, Braithwaite L, Schneider F, Braverman AS, Axiotis C: Estrogen receptor immunocytochemistry in paraffin embedded tissues with ER1D5 predicts breast cancer endocrine response more accurately than H222Sp gamma in frozen sections or cytosol-based ligand-binding assays. Cancer 1996 , 77:2514-2519 
10. Ravdin PM, Green S, Dorr TM, McGuire WL, Fabian C, Pugh RP Carter RD, Rivkin SE, Borst JR, Belt RJ: Prognostic significance of progesterone receptor levels in estrogen receptor-positive patients with metastatic breast cancer treated with tamoxifen: results of a prospective Southwest Oncology Group study. J Clin Oncol 1992, 10:1284-1291

11. De Lena M, Marzullo F, Simone G, Labriola A, Tommasi S, Petroni S, Paradiso A: Correlation between ERICA and DCC assay in hormone receptor assessment of human breast cancer. Oncology 1988, 45:308-312

12. Hawkins RA, Sangster K, Tesdale A, Levack PA, Anderson ED, Chetty U, Forrest AP: The cytochemical detection of oestrogen receptors in fine needle aspirates of breast cancer; correlation with biochemical assay and prediction of response to endocrine therapy. Br J Cancer 1988, 58:77-80

13. Schnitt SJ: Estrogen receptor testing of breast cancer in current clinical practice: what's the question? J Clin Oncol 2006, 24:17971799

14. Rimm DL, Giltnane JM, Moeder C, Harigopal M, Chung GG, Camp RL, Burtness B: Bimodal population or pathologist artifact? J Clin Oncol 2007, 25:2487-2488

15. Harris LN, You F, Schnitt SJ, Witkiewicz A, Lu X, Sgroi D, Ryan PD, Come SE, Burstein HJ, Lesnikoski BA, Kamma M, Friedman PN, Gelman R, Iglehart JD, Winer EP: Predictors of resistance to preoperative trastuzumab and vinorelbine for HER2-positive early breast cancer. Clin Cancer Res 2007, 13:1198-1207

16. Camp RL, Dolled-Filhart M, Rimm DL: X-tile: a new bio-informatics tool for biomarker assessment and outcome-based cut-point optimization. Clin Cancer Res 2004, 10:7252-7259

17. Koscielny S, Terrier P, Daver A, Wafflart J, Goussard J, Ricolleau G Delvincourt C, Delarue JC: Quantitative determination of c-erbB-2 in human breast tumours: potential prognostic significance of low values. Eur J Cancer 1998, 34:476-481

18. Pharoah PD, Day NE, Caldas C: Somatic mutations in the p53 gene and prognosis in breast cancer: a meta-analysis. Br J Cancer 1999, 80:1968-1973

19. Hartmann A, Blaszyk H, McGovern RM, Schroeder JJ, Cunningham J. De Vries EM, Kovach JS, Sommer SS: p53 gene mutations inside and outside of exons 5-8: the patterns differ in breast and other cancers. Oncogene 1995, 10:681-688

20. Hede K: Breast cancer testing scandal shines spotlight on black box of clinical laboratory testing. J Natl Cancer Inst 2008, 100:836-837, 844

21. Wolff AC, Hammond ME, Schwartz JN, Hagerty KL, Allred DC, Cote RJ, Dowsett M, Fitzgibbons PL, Hanna WM, Langer A, McShane LM, Paik S, Pegram MD, Perez EA, Press MF, Rhodes A, Sturgeon C, Taube SE, Tubbs R, Vance GH, van de Vijver M, Wheeler TM, Hayes DF: American Society of Clinical Oncology/College of American Pathologists guideline recommendations for human epidermal growth factor receptor 2 testing in breast cancer. J Clin Oncol 2007 , 25:118-145

22. Camp RL, Chung GG, Rimm DL: Automated subcellular localization and quantification of protein expression in tissue microarrays. Nat Med 2002, 8:1323-1327

23. Camp RL, Neumeister V, Rimm DL: A decade of tissue microarrays: progress in the discovery and validation of cancer biomarkers. J Clin Oncol 2008, 26:5630-5637

24. McShane LM, Altman DG, Sauerbrei W, Taube SE, Gion M, Clark GM: Reporting recommendations for tumor marker prognostic studies (REMARK). J Natl Cancer Inst 2005, 97:1180-1184

25. Linden HM, Haskell CM, Green SJ, Osborne CK, Sledge GW Jr Shapiro CL, Ingle JN, Lew D, Hutchins LF, Livingston RB, Martino S: Sequenced compared with simultaneous anthracycline and cyclophosphamide in high-risk stage I and II breast cancer: final analysis from INT-0137 (S9313). J Clin Oncol 2007, 25:656-661

26. Porter PL, Barlow WE, Yeh IT, Lin MG, Yuan XP, Donato E, Sledge GW, Shapiro CL, Ingle JN, Haskell CM, Albain KS, Roberts JM, Livingston RB, Hayes DF: p2 $7^{\text {Kip } 1}$ and cyclin E expression and breast cancer survival after treatment with adjuvant chemotherapy J Natl Cancer Inst 2006, 98:1723-1731

27. Tubbs R, Barlow WE, Budd GT, Swain E, Porter P, Gown A, Yeh IT, Sledge G, Shapiro C, Ingle J, Haskell C, Albain KS, Livingston R, Hayes DF: Outcome of patients with early-stage breast cancer treated with doxorubicin-based adjuvant chemotherapy as a function of HER2 and TOP2A status. J Clin Oncol 2009, 27:3881-3886

28. McCabe A, Dolled-Filhart M, Camp RL, Rimm DL: Automated quantitative analysis (AQUA) of in situ protein expression, antibody concentration, and prognosis. J Natl Cancer Inst 2005, 97:1808-1815

29. Dolled-Filhart M, McCabe A, Giltnane J, Cregger M, Camp RL, Rimm DL: Quantitative in situ analysis of $\beta$-catenin expression in breast cancer shows decreased expression is associated with poor outcome. Cancer Res 2006, 66:5487-5494

30. Watanabe M, Wallace PK, Keler T, Deo YM, Akewanlop C, Hayes DF: Antibody dependent cellular phagocytosis (ADCP) and antibody dependent cellular cytotoxicity (ADCC) of breast cancer cells mediated by bispecific antibody MDX-210. Breast Cancer Res Treat 1999, 53:199-207

31. Chia S, Norris B, Speers C, Cheang M, Gilks B, Gown AM, Huntsman D, Olivotto IA, Nielsen TO, Gelmon K: Human epidermal growth factor receptor 2 overexpression as a prognostic factor in a large tissue microarray series of node-negative breast cancers. J Clin Oncol 2008, 26:5697-5704

32. Camp RL, Dolled-Filhart M, King BL, Rimm DL: Quantitative analysis of breast cancer tissue microarrays shows that both high and normal levels of HER2 expression are associated with poor outcome. Cancer Res 2003, 63:1445-1448

33. Koscielny S, Terrier P, Spielmann M, Delarue JC: Prognostic importance of low c-erbB2 expression in breast tumors. J Natl Cancer Inst 1998, 90:712

34. Binder SR: Autoantibody detection using multiplex technologies, Lupus 2006, 15:412-421

35. Fountaine TJ, Wincovitch SM, Geho DH, Garfield SH, Pittaluga S: Multispectral imaging of clinically relevant cellular targets in tonsi and lymphoid tissue using semiconductor quantum dots. Mod Patho 2006, 19:1181-1191

36. Gannot G, Tangrea MA, Erickson HS, Pinto PA, Hewitt SM, Chuaqui RF, Gillespie JW, Emmert-Buck MR: Layered peptide array for multiplex immunohistochemistry. J Mol Diagn 2007, 9:297-304

37. Gusev Y, Sparkowski J, Raghunathan A, Ferguson H Jr, Montano J, Bogdan N, Schweitzer B, Wiltshire S, Kingsmore SF, Maltzman W, Wheeler V: Rolling circle amplification: a new approach to increase sensitivity for immunohistochemistry and flow cytometry. Am J Patho 2001, 159:63-69

38. Szeszel MK, Crisman CL, Crow L, McMullen S, Major JM, Natarajan L, Saquib A, Feramisco JR, Wasserman LM: Quantifying estrogen and progesterone receptor expression in breast cancer by digita imaging. J Histochem Cytochem 2005, 53:753-762

39. Collins LC, Botero ML, Schnitt SJ: Bimodal frequency distribution of estrogen receptor immunohistochemical staining results in breast cancer: an analysis of 825 cases. Am J Clin Pathol 2005, 123:16-20

40. Nadji M, Gomez-Fernandez C, Ganjei-Azar P, Morales AR: Immunohistochemistry of estrogen and progesterone receptors reconsidered: experience with 5,993 breast cancers. Am J Clin Pathol 2005, 123:21-27

41. McGuire WL: Quantitation of estrogen receptor in mammary carcinoma. Methods Enzymol 1975, 36:248-254

42. Osborne CK, Yochmowitz MG, Knight WA 3rd, McGuire WL: The value of estrogen and progesterone receptors in the treatment of breast cancer. Cancer 1980, 46:2884-2888

43. Giltnane JM, Molinaro A, Cheng H, Robinson A, Turbin D, Gelmon K Huntsman D, Rimm DL: Comparison of quantitative immunofluorescence with conventional methods for HER2/neu testing with respect to response to trastuzumab therapy in metastatic breast cancer Arch Pathol Lab Med 2008, 132:1635-1647

44. Hayes DF: Quantitative measures of oestrogen receptor and ERBB2 expression. Lancet Oncol 2007, 8:184-185

45. Pawlowski V, Révillion R, Hornez L, Peyrat JP: Low concentrations of c-erB-2 m RNA (real time RT-PCR) are associated with poor prognosis in 404 unselected primary breast cancers. Proc Am Assoc Cancer Res 1999, 40:1355

46. Sørlie T, Perou CM, Tibshirani R, Aas T, Geisler S, Johnsen H, Hastie $\mathrm{T}$, Eisen MB, van de Rijn M, Jeffrey SS, Thorsen T, Quist H, Matese JC, Brown PO, Botstein D, Eystein Lonning P, Borresen-Dale AL: Gene expression patterns of breast carcinomas distinguish tumor subclasses with clinical implications. Proc Natl Acad Sci USA 2001 98:10869-10874

47. Hayes DF, Thor AD, Dressler LG, Weaver D, Edgerton S, Cowan D, 
Broadwater G, Goldstein LJ, Martino S, Ingle JN, Henderson IC, Norton L, Winer EP, Hudis CA, Ellis MJ, Berry DA: HER2 and response to paclitaxel in node-positive breast cancer. N Engl J Med 2007, 357:1496-1506

48. Carey LA, Dees EC, Sawyer L, Gatti L, Moore DT, Collichio F, Ollila DW, Sartor $\mathrm{Cl}$, Graham ML, Perou CM: The triple negative paradox: primary tumor chemosensitivity of breast cancer subtypes. Clin Cancer Res 2007, 13:2329-2334

49. Nielsen TO, Hsu FD, Jensen K, Cheang M, Karaca G, Hu Z, Hernandez-
Boussard T, Livasy C, Cowan D, Dressler L, Akslen LA, Ragaz J, Gown AM, Gilks CB, van de Rijn M, Perou CM: Immunohistochemical and clinical characterization of the basal-like subtype of invasive breast carcinoma. Clin Cancer Res 2004, 10:5367-5374

50. Ross DT, Kim CY, Tang G, Bohn OL, Beck RA, Ring BZ, Seitz RS, Paik S, Costantino JP, Wolmark N: Chemosensitivity and stratification by a five monoclonal antibody immunohistochemistry test in the NSABP B14 and B20 trials. Clin Cancer Res 2008, 14:6602-6609 